\title{
EL SÓCRATES DE ROSSELLINI: UNA LECTURA DE LA ANDREIA COMO VIRTUD CÍVICA
}

\section{ROSSELLINI'S SOCRATES: A READING OF THE ANDREIA AS A CIVIC VIRTUE}

\author{
IGNACIO PAJÓN LEYRA* \\ Facultad de Filosofía \\ Universidad Complutense de Madrid
}

Resumen: El presente artículo estudia la figura de Sócrates en el largometraje homónimo de Rosselini de 1971, a través del análisis ofrecido por el director de la evolución de la noción clásica de andreia como virtud bélica hacia una nueva configuración enmarcada en el ámbito cívico de la polis, entendida como fusión cohesionada de las características tradicionales y las nuevas exigencias de la vida en la ciudad. La figura de Sócrates es propuesta como punto de giro de algunas de las prenociones conformadoras de nuestra sociedad tales como la tensión ético-política, el deber cívico o las resistencias a la realización individual en el marco social contemporáneo.

Palabras ClaVE: Sócrates, cine, virtud, Roberto Rossellini, política

ABSTRACT: This article studies the figure of Socrates in Rosellini's eponymous 1971 film, through the analysis offered by the director of the evolution of the classical notion of andreia as a war virtue to a new configuration, framed in the civic realm of the polis,

\footnotetext{
" Profesor Titular interino de Filosofía Antigua. Departamento de Historia de la Filosofía, Estética y Teoría del Conocimiento, Facultad de Filosofía, Universidad Complutense de Madrid, Ciudad Universitaria, 28040 Madrid. Email: ipajon@ucm.es, financiación: Proyecto de Investigación "El escepticismo pirrónico-empírico y el escepticismo académico en su desarrollo histórico". (Ref. FFI2016-77020-P).
} 
understood as a cohesive virtue of traditional features and the new demands of life in the city. The figure of Socrates is proposed as a turning point for some of the preconceptions shaping our society such as ethical-political stress, civic duty, and resistance to individual fulfillment in the contemporary social context.

KEYwORDS: Socrates, cinema, virtue, Roberto Rossellini, politics

\section{Introducción: el Sócrates de Rossellini}

Entre las películas que, hacia el final de su carrera, Roberto Rossellini dedicó a algunas de las grandes figuras de la historia del pensamiento, una de las que más repercusión ha tenido es la que en 1971 centró en la vida, el pensamiento, el proceso y la muerte de Sócrates. La película tiene una orientación fundamentalmente pedagógica y divulgativa, lo que no impide que trate, en ocasiones con bastante detenimiento, algunas de las principales concepciones filosóficas socráticas; y además, en última instancia puede decirse que la propia orientación fílmica de Rossellini ejerce de lectura de la personalidad y la obra del protagonista, es decir, que la película es en sí misma una interpretación (sin pretensiones de originalidad ni de novedad hermenéutica) de la filosofía socrática.

El modo en que la película, junto con las que el director italiano dedicó a Descartes, Agustín de Hipona, o Pascal, se orienta hacia la exposición del filosofar desde su encarnación corporal, vital y ejemplar mediante la biografía, es algo que ya ha sido tratado y trabajado con frecuencia por los especialistas desde que Jacques Rancière lo resaltase en su texto "El cuerpo del filósofo" (Rancière, 2012, 87-101). Sin embargo, quizá la especificidad de la lectura rosselliniana de la filosofía socrática ha pasado algo más inadvertida. Y a la elucidación del marco referencial de dicha lectura es a lo que dedicaremos las siguientes páginas.

La película se sitúa desde sus primeras secuencias en un contexto de inestabilidad política generado a raíz del conflicto entre Atenas y Esparta, al final de la Guerra del Peloponeso. Aunque el enfrentamiento ideológico y social entre lo que podríamos llamar el "modo ateniense" y el "modo espartano" es mucho más amplio y se remonta mucho más en el tiempo, la mirada de Rossellini se centra en este punto concreto del prolongado enfrentamiento para situar en él el origen del conflicto dramático. Así, la narración fílmica arranca con el establecimiento del gobierno de los treinta tiranos, impuesto por Esparta en el 404 a. C., y el 
acto (tanto estratégico como simbólico) de derribo de las murallas atenienses por los victoriosos espartanos.

No se trata meramente de un ejercicio de contextualización histórica, sino más bien al contrario: una exposición de algunas de las consecuencias que se nos muestran como derivadas de una más profunda problemática. La tensión entre proespartanos y proatenienses, entre tiranos y defensores de la recién caída democracia, se manifiesta como encarnada por dos figuras prominentes: el estratego Alcibíades, discípulo de Sócrates que ha representado un papel de especial importancia en la fallida defensa de la ciudad, y Critias, integrante de la nueva tiranía de los treinta impuesta por los vencedores, que también fue discípulo (aunque siempre se nos aclara que menos aventajado) de un Sócrates hasta ese momento ausente de la escena. Así, democracia y tiranía, razón y pasión, justicia e injusticia, autogobierno ateniense y ocupación espartana, aparecen como dos facetas interpretativas de una misma enseñanza: la de un Sócrates de quien todos hablan, pero a quien el director de la película tarda en conceder la palabra por sí mismo. Y el acto de derribo de la muralla ciudadana se muestra como el instante crucial en el que se borra la frontera física de la polis, y con ello se desdibujan también los límites simbólicos que la definen. Con las murallas en pie, todo ateniense forma parte de un conjunto unitario señalado por un perímetro a un tiempo defensivo y demarcador. Pero sin ellas esa unidad se diluye, con lo que la identificación ciudad-ciudadano entra en crisis. Ese será el contexto escénico en el que los personajes históricos habrán de moverse: una Atenas difusa, en lucha por redefinirse y por volver a ser fundamento identitario para sus ciudadanos.

Pasado ese exordio inicial, Sócrates se hace por fin presente a la narración, y aparece justo como el público lo esperaría: anciano (siempre anciano, con independencia de los saltos cronológicos de la acción), afable, rodeado de apasionados discípulos y atacado injustificadamente por airados (e inexplicables) detractores.

La primera ocasión en la que el filósofo puede exponer su postura intelectual nos muestra algunos de los conceptos clave de la imagen más popular del socratismo: ignorancia, saber, opinión, aunque al espectador avezado en la filosofía antigua se le hará también evidente un cierto marco de lectura en dicha exposición: el Sócrates de Rossellini es sin duda un Sócrates muy platónico. Y no sólo por ser visto desde una óptica que no escatima el elogio y la admiración, ${ }^{1}$

\footnotetext{
${ }^{1}$ Otras visiones de Sócrates, más críticas, como la que ofrece Aristófanes, no han sido ignoradas por Rossellini, pero en ningún caso ejercen de escenario narrativo como sí lo hace la
} 
sino también porque el director italiano expone su filosofía desde los diálogos platónicos, aludiendo a ellos con frecuencia como su principal fuente histórica y como testimonio temático predominante. ${ }^{2}$

La imagen de Sócrates es, además, muy compacta desde el punto de vista dramático. Aparece encarnando el ejemplo del buen ciudadano. Se le muestra, por tanto, como manifestación viviente del modo griego de concebir la vinculación del ciudadano con la ciudad (Calvo, 1995,105-109). Sin duda alguna, hay en este Sócrates la misma conciencia de pertenencia a Atenas que nos transmiten los textos antiguos sobre el Sócrates histórico. Pues en efecto sabemos que Sócrates fue un ateniense ejemplar en lo que respecta a la asunción de sus responsabilidades ciudadanas, en su doble vertiente cívica y bélica. Cumplió adecuadamente sus obligaciones militares. Participó en la guerra tres veces como hoplita: en Potidea, en 432, donde salva la vida a Alcibíades; en Delion, en 424, batalla perdida por el bando ateniense de la que el general Laques llegó a afirmar que si todos los atenienses hubiesen luchado como Sócrates, la batalla se habría ganado; y la más reciente, en Anfípolis, en 422. Y este pasado militar heroico es algo que Rossellini, a lo largo de su narración cinematográfica, no dejará de recordarnos.

\section{La virtud de la andreia}

El vínculo de Sócrates con la defensa armada de la ciudad está arraigado en su concepción de las responsabilidades que todo integrante de la polis debe

visión platónica. Rancière, en cambio, manifiesta también esta otra cara del personaje socrático. Así, por ejemplo: "Sócrates, a través de sus interrogaciones, conduce al esclavo de Menón a reconocer las verdades matemáticas que ya están en él. Hay ahí tal vez el camino de un conocimiento, pero en ningún caso el de una emancipación. Por el contrario, Sócrates debe llevar de la mano al esclavo para que éste pueda encontrar lo que está en sí mismo. La demostración de su saber es al mismo tiempo la de su impotencia: no caminará nunca solo, y por otra parte nadie le pedirá que camine sino para ejemplificar la lección del maestro. Sócrates interroga a un esclavo que está destinado a serlo siempre." (Rancière, 2003, 51)

${ }^{2}$ Cabe preguntarse, sin embargo, por qué Platón mismo no aparece como personaje en una película biográfica sobre Sócrates como esta. Y quizá el motivo sea precisamente que el Sócrates de Rossellini es Sócrates y es Platón. Por ello, el realizador italiano se ve movido a utilizar una única voz para exponer este pensamiento de manera clara, y así no confundir al espectador empleando dos expositores distintos para mostrar una sola filosofía. En gran medida esto es lo que hizo Platón al excluirse a sí mismo como personaje en sus diálogos, lo que nos permite ver en cierto modo el largometraje de Rossellini, salvadas las distancias, como análogo a los propios diálogos socráticos. 
asumir por el mero hecho de serlo. Tan importante es, de este modo, cumplir las leyes o participar en los órganos de decisión, como defender de manera activa las fronteras del espacio ciudadano común. Pero Sócrates no es sólo alguien que se ha limitado a cumplir con esa obligación formal, sino alguien que ha destacado de manera muy significativa en varios momentos de su vida en la defensa de Atenas por las armas. Alguien, pues, que según la mentalidad helena aparece como dotado de manera destacada en lo que respecta a la virtud de la andreia.

Una gran parte del discurso fílmico de Rossellini gira alrededor de esta virtud, y de su articulación con el resto de virtudes tradicionales griegas. Como es sabido, hay una prenoción helénica de la mutua implicación de las virtudes ciudadanas: todas ellas se ejercen en la interacción social, y todas ellas parecen coherentes entre sí, e incluso necesarias cada una para las demás. Así, ser sabio no solamente no es impedimento para ser justo, sino que parece ser algo en cierta medida de importancia para poder ser justo. $\mathrm{Y}$ algo similar ocurre con el ser prudente o con el ser templado. Todas ellas son virtudes ejercidas en el seno de la polis misma, entre sus integrantes. Y todas parecen darse en una cierta armonía conjunta. Todas menos una: la andreia, traducida unas veces como valentía y otras como fortaleza; la virtud del varón. ${ }^{3}$

A diferencia del resto de virtudes tradicionales, la andreia no es una virtud que pueda ejercerse, según su forma tradicional de ser entendida, en el contexto social normal de la polis. Es una virtud agónica que exige un contendiente frente al cual pueda desplegarse. ${ }^{4}$ Mientras que el resto de virtudes se ejercen intramuros, dentro de los límites de la ciudad, la andreia es concebida como una virtud especial para una situación especial: la virtud de las situaciones de guerra, en las que ser prudente, justo o moderado puede no ser el comportamiento más excelente.

Por ese motivo, mientras que ser justo, ser prudente y ser moderado parecen implicarse mutuamente de algún modo, mostrar andreia es algo que casi parece exigir la suspensión del resto de virtudes. ${ }^{5}$ La andreia consiste de modo

\footnotetext{
${ }^{3}$ Andreia, de aner, andrós (varón), es en la mentalidad griega de la época la virtud propia del hombre frente a aquellos que, siendo ánthropoi, están impedidos por su propia naturaleza para mostrarse virtuosos en este sentido (es decir, mujeres y niños). Es, por tanto, una valentía concebida como una forma de virilidad.

${ }^{4}$ Véase Pl. Grg. 491 b-e. Cfr. también Pajón, 2004, 170; Cullyer, 2003, 213-233.

${ }^{5}$ Ya Protágoras manifiesta, en el diálogo que lleva su nombre, que a diferencia del resto la andreia puede darse sin el concurso de ninguna de las otras virtudes. (Pl. Prt. 349 a-d; 359
} 
específico, en su formulación tradicional griega, en procurar el bien de los amigos y el daño de los enemigos, algo que excluye las ideas de moderación, prudencia $y$ en especial justicia, y las sustituye por un mero alinearse con o contra el que ejerce dicha virtud.

Se trata, pues, de la areté del campo de batalla, en el que la línea de escudos entrelazados de los hoplitas sustituye la muralla de la ciudad marcando el límite entre el "dentro" en el cual el otro es el conciudadano (ante el que se debe ser justo, moderado y prudente), y el "fuera" en el cual todo posible otro queda excluido del marco político y definido, por defecto, como enemigo. El escudo del hoplita, así, no defiende solo al hoplita que lo porta, sino al que se sitúa a su lado (y por tanto frente al mismo oponente), y dejarlo caer es la peor cobardía, porque a un tiempo quiebra la defensa y permite que se desdibuje la línea divisoria que define y demarca la identidad y la alteridad puestas en conflicto.

El Sócrates hoplita, de este modo, ha ejercido su papel de defensa de la identidad ateniense en ocasiones sucesivas y con gran éxito, ganándose con ello la consideración de sus conciudadanos. Valentía y capacidad de sacrificio son los rasgos principales en los que ha destacado. Algo por lo que la polis debe estarle agradecida. Él mismo aludirá a ese mérito en el transcurso de su defensa:

Cuando los jefes que vosotros elegisteis para mandarme en Potidea, en Anfípolis y en Delion me asignaron un puesto, aguanté como el primero donde ellos me habían colocado y arrostré el peligro de muerte. (Platón. Apología, 28 e.)

La identificación de este Sócrates soldado con este modo de asumir las obligaciones bélicas ciudadanas no supone, sin embargo, que el Sócrates filósofo, al menos tal y como lo conocemos a través del testimonio de Platón, asimilase del mismo modo el papel teórico de la visión tradicional de la virtud de la andreia. Al contrario: como es sabido, su intelectualismo moral le lleva a sostener una plena unidad de las virtudes. Y para poder dar sentido a esa unidad, Sócrates se verá obligado a replantear el significado mismo de la andreia. Al contrario que en la visión tradicional, en la cual la valentía se ejerce frente al peligro exterior, el replanteamiento socrático dibuja un nuevo sentido de la andreia en el que el peligro frente al que debe ser valiente el valiente es el peligro interior. El nuevo enemigo es, así, un enemigo interno: en un primer momento el miedo mismo y otros sentimientos también propios del contexto agónico, como el dolor o

a-c; Jaeger, 1980, 490-507). 
el sufrimiento. Pero casi de inmediato ese nuevo sentido socrático-platónico se amplía para poder aplicarse sobre las pasiones, placeres y deseos que, en el contexto agónico interior (el que enfrenta en combate a alma y cuerpo) se alinean con lo corporal.

La nueva andreia se manifiesta, así, como esa virtud represora de la voluntad por la que Nietzsche alineará a Sócrates entre los negadores de la vida. Rossellini, en cambio, no hará muestra ninguna de concordar con Nietzsche a este respecto. Su visión de la figura de Sócrates es, antes que nada, la de un hombre dotado de valentía. Y la valentía de la que le caracteriza en su película bordea tanto el sentido antiguo como el nuevo de la virtud correspondiente.

Sócrates es mostrado como alguien que ha sido un soldado y un ciudadano ejemplar, y su ejemplaridad es la del agón extramuros tanto como la de la cotidiana lucha civil en el interior de la polis. Se alude, así, al episodio de su vida en el que no apoyó la causa judicial conjunta que, en contra de la legalidad vigente, la mayoría de Atenas quería promover contra varios de sus generales. Se trataría, así, de una más de las veces que ejerce su valentía al ponerse del lado de la ley frente al lado de la voluntad de las masas, sin temer las probables consecuencias en su contra (Calvo, 1995, 107-109). Y algo más avanzada la película, se muestra expresamente la ocasión en que el gobierno de los treinta tiranos intentó implicar a Sócrates en su modo de ejercer el poder, al reclamarle que detuviera, junto con otros ciudadanos, a León de Salamina (Calvo, 1995, 107-109). Sócrates, por supuesto, se negó a participar, desobedeciendo así una orden de la autoridad ciudadana, y mostrando que aunque para él la valentía cívica es análoga a la militar, y consiste principalmente en el aguante, no se puede identificar con la obediencia ciega.

La andreia cívica, pues, al volcarse sobre el interior del espacio político se ha transformado en un acatamiento de la ley y del dictado de la justicia, una fuerte asunción de la responsabilidad, y si la circunstancia lo requiere, una desobediencia explícita de la injusticia que casi nos recuerda a nuestro contemporáneo concepto de desobediencia civil.

Valentía también es, así, la valentía de enfrentarse al poder establecido si es para defender algo que, o bien no es propiamente legal, o bien es manifiestamente injusto. 
Pero si esto es así, ¿¿de qué modo se compatibiliza esa forma de arriesgada, meritoria y valiente desobediencia con el acatamiento de la ley injusta que, como sabemos, le conducirá a su final? En primer lugar, Sócrates comparte con los sofistas la tesis de que el nómos es convencional. La ley es el resultado de un acuerdo, un pacto ciudadano (que Sócrates no interpreta como pacto entre los integrantes de la polis, sino como pacto de cada ciudadano con la propia legalidad). Pero esto, lejos de restarle validez a las leyes vigentes, les añade valor. En todo momento quien está en la polis está confirmando la aquiescencia con sus leyes. Quien está en desacuerdo con ellas es libre de marcharse, dejando así de darles su beneplácito como marco de interacción social humana. Y quien permanece libremente en la polis, queda obligado por ese acto voluntario a cumplir su legislación.

En ese sentido, la diferencia entre la desobediencia socrática ante las decisiones ilegales o alegales tomadas por el poder contra la injusticia, y su asunción de su muerte a pesar de considerarla del mismo modo como injusta, es que la injusticia sufrida es neutral respecto del nuevo uso interiorizado de la andreia, mientras que la colaboración en el acto de cometer injusticia contra otros (por miedo, por ambición, por placer o por el motivo que sea) viene promovida por esos enemigos interiores que el valiente debe emplearse en derrotar.

\section{Figuras de contraste}

La necesidad de Rossellini de mostrar esta valentía socrática como destacada e incluso excepcional le lleva a situar la figura de Sócrates, a lo largo de toda la narración fílmica, en contraste con toda una serie de contrapuntos que hagan aparecer ante el espectador esa excepcionalidad. Así, Critón aparece en momentos sucesivos ocupando el lugar del discípulo bien dispuesto, deseoso de alcanzar la valía del maestro pero desconocedor de los elementos a los cuales debe oponerla. En segundo lugar, Jantipa, esposa de Sócrates, rodeada por los niños, ejerce el papel de aquellos que no están destinados por su naturaleza a tener andreia, pero que sin embargo pueden llegar con el tiempo a entreverla, comprenderla y valorarla en lo que tiene de virtud, aunque no la puedan ejercer. Por último, el contrapunto máximo lo suponen los acusadores, encabezados por el pusilánime Mélito, un "pobre hombre" de escaso entendimiento en el que la propia expresión facial del actor que lo interpreta se encuentra orientada a marcar la extrema diferencia con Sócrates: siempre dejándose llevar por una 
gran afectación que transmite su miedo, su envidia, su deseo de prestigio, su turbación, etcétera, frente a la serenidad socrática. Pero además también aparece en el bando de los acusadores, y con un protagonismo mayor que el de Ánito y Licón, el comediógrafo Aristófanes. Es incuestionable que su comedia Las nubes, protagonizada por un muy caricaturizado Sócrates, supuso uno de los factores principales de la extensión por Atenas de una importante mala imagen del filósofo. En ella, como en la primera mención de Aristófanes en la película, se incluye una doble acusación contra la actividad socrática: en primer lugar, la de promover el ateísmo científico ofreciendo explicaciones de los fenómenos que dejan de lado las tradicionales explicaciones mitológicas. En segundo lugar, la de promover la injusticia mediante la enseñanza de argucias dialécticas. Con ellas, el cómico mostraba su posición contraria a los cambios sociales que la filosofía había promovido con gran rapidez en el ambiente cultural griego: en primer lugar, cambios de orden teológico, suscitados por la tradición peri phýseos desde Mileto en adelante; y en segundo lugar, cambios sociales de los que cabía responsabilizar a los sofistas. Aristófanes, de este modo, acusa a los filósofos en general de ser contrarios a la tradición (sea a la tradición ritual y religiosa, sea a la social y política), y para ello encarna su crítica en el más destacado filósofo de su momento: Sócrates.

Sin embargo, en este punto Rossellini opta por no incorporar ningún elemento de la parodia de Aristófanes a su visión de Sócrates. La considera un mero error del cómico y del bando de los acusadores en general, que no han sido capaces de distinguir lo que hace un sofista de lo que hace un filósofo físico, y que además han confundido a Sócrates con Anaxágoras. El reflejo de la situación filosófica de la Atenas del momento en Las nubes, en cambio, hemos de admitir que es mucho más certero de lo que parece, ${ }^{6}$ y que no proviene de errores ni de malas interpretaciones, sino de un gran conocimiento de antecedentes y líneas de influencia que han acabado por conformar un panorama concreto. En efecto, Sócrates puede y debe relacionarse con Anaxágoras, pues de la presencia de elementos de la física de Anaxágoras (junto con la más antigua de Anaxímenes) en la cosmovisión de Arquelao es de la que se conformó el pensamiento perì phýseos del joven Sócrates (Betegh, 2013, 87-106; Vander Waerdt, 1994, 48-86). Y esa

\footnotetext{
${ }^{6}$ Sobre esta cuestión existe multitud de bibliografía reciente, cuya exposición detenida se saldría de los límites de este estudio. Sin embargo, me permito remitir al lector al reciente trabajo de Christopher Moore (Moore, 2015, 534-551) y a la panorámica de contexto que ofrece el conjunto de estudios contenido en el libro sobre el tema editado por André Laks y Saetta Cottone Comedie et philosophie: Socrate et les "Presocratiques" dans les Nuées d'Aristophane (Laks y Saetta Cottone eds., 2013).
} 
herencia es la que aparece reflejada en Las nubes, junto con el añadido de su segunda etapa filosófica: la antropológica, social y moral, influida por el modo de argumentar y de manifestarse de la sofística. Así, Sócrates es el símbolo perfecto para Aristófanes de los dos males de la filosofía que, según él, acosan a la sociedad griega. De joven fue uno de los que ponían en cuestión el papel de los dioses; de viejo, uno de los que defienden posiciones inverosímiles y las hacen parecer justificadas. Y por ambas cosas en la mención de su nombre pueden integrarse los elementos principales de la visión negativa de la filosofía que los sectores más conservadores de la sociedad ateniense del momento han construido como explicación de la decadencia de dicha ciudad. Es decir, tanto por su pasado perì phýseos como discípulo de Arquelao como por su presente de pensador moral y antropológico como dialogador irónico, Sócrates representa mejor que nadie para la Atenas más conservadora el fenómeno mismo de la filosofía en todo lo que ha tenido de potencia transformadora del panorama intelectual. Así, aunque no se pueda ver ignorancia o error interpretativo en Aristófanes, tampoco puede negarse el efecto negativo que su comedia tuvo sobre la imagen social de Sócrates entre sus conciudadanos, sobre todo a la vista de la presencia precisamente de esos dos elementos (físico y dialéctico) en la acusación que sufrirá años más tarde.

Por lo que respecta al papel de Jantipa en la creación de Rossellini, a su rol de contrapunto se le añade la característica de marcar cierta evolución. Su primera escena en la película es de pleno enfrentamiento con Sócrates, si bien un enfrentamiento cotidiano y familiar, aunque no por ello menos marcado por la oposición directa. Lo que podría parecer una mera escena costumbrista poco relacionada con el tema filosófico general del discurso de su contexto, se desvela como uno de los núcleos de articulación del modo de comprensión socrático de la andreia. El desencadenante de la discusión es el regreso a casa de Sócrates después de varios días, cuando en un principio había salido solo a comprar comida. Este arranque de la escena recuerda en cierto modo al clásico tópico del filósofo como sabio distraído que nos acosa desde la caída de Tales al pozo (y que también forma parte de la parodia de Aristófanes contra el propio Sócrates), aunque en este caso la construcción del discurso por parte de Rossellini parece convertirlo en un elogio de la dedicación a los elevados temas filosóficos y el desprendimiento de los prosaicos temas cotidianos, en vez de en una burla.

Sin embargo, la continuación de la discusión con Jantipa revela un segundo tópico subyacente: el conflicto no se limita a una mera cuestión de desatención. También hay un desacuerdo doméstico sobre la propia forma de actuar de Sócrates en su actividad como dialogador: cobrar o no cobrar. La actividad de Sócrates 
es, como muchas veces se ha señalado, ${ }^{7}$ muy similar a la de los sofistas. Ambos hablan con los atenienses, y ambos cumplen con ello una cierta labor educadora, por muy diferente que ellos consideren que es. Lo que los diferencia de veras, más que la actividad en sí, es el hecho de que Sócrates no cobra por llevar a cabo su labor, mientras que los sofistas, concibiéndose a sí mismos como un oficio más, exigen un precio por sus servicios.

El hecho de que Jantipa le reclame que empiece a cobrar a quienes le escuchan, y que sea precisamente ella, una mujer, alguien carente de la virtud del varón, quien defienda el cobro por el uso del lógos, muestra la contraposición precisa de la que se está tratando. Sócrates es quien es valiente, quien emplea su razón contra lo que debe emplearse, mientras que los sofistas solo fingen valentía, pero en realidad están dominados por el enemigo interior al que deberían enfrentarse.

Pero no cobrar, como Jantipa señala, implica también no tener qué comer. Y al igual que unos minutos más tarde en el metraje, en el núcleo de una discusión sobre la importancia esencial del valor, será Jantipa quien aparezca (aterrorizada) para comunicar a Sócrates que la autoridad le convoca (y mostrar con su pánico el opuesto de la serenidad del valiente), también ahora Jantipa muestra el opuesto del comportamiento considerado virtuoso: dicho en pocas palabras, Jantipa se preocupa por comer, algo que en el metadiscurso socrático aparece como justo lo contrario de la andreia.

\section{La reorientación socrática del valor}

¿Quién es, pues, el dotado de andreia? El fuerte, en un muy concreto sentido de la fuerza que podemos encontrar en la discusión sobre los poderosos sostenida a continuación en la película, o más explícitamente aún en la discusión que en el diálogo platónico Gorgias mantiene Sócrates con Calicles. ${ }^{8}$ De hecho, el planteamiento expuesto por Calicles en ese diálogo es en última instancia una reacción ante la exposición por parte de Sócrates de su teoría de la virtud, y en especial de su reformulación de la virtud de la andreia respecto a la visión

\footnotetext{
${ }^{7}$ Merece la pena marcar como ejemplo destacado la reflexión de Jankélévitch en La ironía o la buena conciencia (Jankélévitch, 1982, 12).

${ }^{8} \mathrm{Pl}$. Grg. 481a-527e.
} 
tradicional. La distorsión que este replanteamiento socrático (o socrático-platónico) produce en el sentido del término es tal que provoca la incomprensión de Calicles, incapaz de concebir cómo podría la andreia identificarse con la autocontención frente a los deseos y placeres.

Al contrario que Sócrates, Calicles es partidario de mantener la orientación hacia el exterior del ejercicio agónico de esta virtud. El enemigo del valiente es exterior; es el otro como impedimento para alcanzar la satisfacción de esos deseos y placeres. Pero al igual que Sócrates, Calicles también lo ha reformulado, pues su sentido del valor ya no se ejerce en exclusiva, ni siquiera primordialmente, fuera de los límites de la polis. No es ya, por tanto, la virtud del espacio excepcional de la guerra, sino una más de las virtudes ciudadanas, con lo que el ámbito político adquiere las características del conflicto bélico, y el ciudadano se transforma en enemigo para el gobernante si este es lo bastante valeroso, si tiene suficiente valía, como para asumir dicha conflictividad (Menzel, 1964, 20).

Calicles es, en este sentido, un cierto antecedente de Nietzsche, tanto por plantear la crítica de la moral vigente como aquietadora de los fuertes que Nietzsche después compartirá, como por oponerse con firmeza a la reformulación ascética y anticorporal de la valentía en Sócrates.

Como Nietzsche, Calicles se muestra como afirmador de la vida, pero en un sentido quizá menos sutil que el nietzscheano: afirmación de la vida como defensa de la misma frente al oponente siempre exterior que amenaza con destruirla, limitarla o contenerla. Y desde la óptica socrática esto no es más que un modo soterrado de expresar falta de andreia como miedo al dolor, al sufrimiento, a la pérdida del poder o a la muerte. Es decir, dado el replanteamiento socrático, la postura sofístico-política general, expuesta por el personaje de Calicles, es más bien la propia de un cobarde que la de un verdadero valiente (Pajón, 2004, 168172; Menzel, 1964, 104-107).

No es casual que Rossellini mencione la muerte de Calicles tras la valiente rebelión de Trasíbulo, ${ }^{9}$ en el minuto 34:16, a pesar de que Calicles no es ningún personaje histórico que conozcamos (Calvo, 1995, 84). Se trata, pues, de un acto

\footnotetext{
${ }^{9}$ Nótese que esta acción bélica cumple la función en la narrativa fílmica de Rossellini de ejemplificar el valor de la valentía frente al poder injustamente establecido, mostrándose como la última aparición del valor tradicional antes del establecimiento como modelo del nuevo valor cívico socrático.
} 
valeroso que sirve en la película para simbolizar la muerte de los planteamientos cobardes carentes de verdadera andreia.

La falta de andreia en Jantipa, en cambio, permanece en escena para permitir una evolución en la valoración de la figura de Sócrates desde los ojos de quien no alcanza su nivel de valía. Así, de la escena inicial de pleno enfrentamiento doméstico, la actitud de Jantipa se va transfomando, primero en preocupación como la expresada cuando Sócrates es convocado para ser reconvenido (y forzado sin éxito a cometer injusticia), y después en plena admiración en el momento trágico de la muerte. ${ }^{10}$

Así, Jantipa y los niños son expulsados de la escena en presencia del verdugo y la cicuta para evitar sus lamentos, y Sócrates reprende a sus discípulos, que no han sido expulsados y pueden contemplar el proceso mismo de envenenamiento. "Mostrad fortaleza", les dice; pues si sucumben a la tristeza y el llanto se estarán comportando como mujeres o niños, y no como hombres de valía. Y eso a pesar de la clara conciencia de que no han entendido aún el motivo principal por el que Sócrates se ve movido a no temer a la muerte.

\section{Conclusión: la valentía cívica}

A partir de este punto, la escena se escinde en dos: la interior, reservada al maestro y sus discípulos, y la exterior, en la que todo ateniense, todo ciudadano, todo ser humano tiene algo que decir. Dentro se plantea la pregunta por el alma, en los términos que nos son tan bien conocidos gracias a los diálogos platónicos. Afuera, Jantipa da la muestra definitiva de su transformación valorativa, a la que la orientación didáctica de la película pretende habernos movido también como espectadores: lejos ya de la actitud de incomprensión de la postura de Sócrates, Jantipa habla ahora a sus hijos. Y lo hace marcándoles el comportamiento y la figura de su padre como modelo. Cuando crezcan, les dice, todo el mundo

\footnotetext{
${ }^{10}$ De este modo, se cumple a la perfección el análisis general sobre el cine de Rossellini llevado a cabo por Rancière en otro de sus textos sobre el tema: "Ascetismo e idolatría son los dos polos entre los que viajan los protagonistas - sobre todo las mujeres - de Rossellini: por un lado, la renuncia a las imágenes del espejo, a los valores fariseos y a la seguridad del propio hogar (...); por otro, la crítica a las "puras imágenes ascéticas” (...). El escándalo que da su materia al cine de Rossellini se mantiene siempre en un punto de ambigüedad, en el cruce entre los trayectos de la renuncia y la encarnación.” (Rancière, 2005, 153).
} 
tendrá los ojos fijos en ellos porque son los hijos de Sócrates, el ciudadano más valeroso de Atenas.

El coraje de Sócrates no es el del guerrero, que disimula el miedo sin comprender la verdad sobre su vida y sobre su alma, sino el coraje tranquilo de quien ha comprendido y sabe que no tiene motivo para temer. Así, el mandato final de Jantipa a sus hijos lo muestra claramente como el comportamiento que debe ser adoptado; como el resultado de un cambio de valoración de la virtud de la valentía que ha suplantado la antigua forma épica de oposición al enemigo. El temor, la lamentación o el llanto ante la mortalidad no están justificados. Y aunque Jantipa no pueda superar su condición natural y por tanto no pueda dejar de sollozar en la propia escena, puede haber entendido el cambio de actitud respecto de la valía ciudadana, y por ello puede conminar a sus hijos (y al tiempo conminarnos a nosotros, hijos de Sócrates en tanto que ciudadanos de Occidente): "No lloréis, sois hijos de un héroe."

La andreia tradicional, la de Aquiles, ha quedado obsoleta. Una nueva forma de valentía para tiempos de paz y de política, la andreia del héroe Sócrates, ha venido para sustituirla. Y en ella se produce la plena fusión de los sentidos del valor: el valor como valía se identifica y se integra con el valor como valentía produciendo una virtud cohesionada y carente de paradojas para su desempeño como virtud en la ciudad.

Tras esto solo queda ya el advenimiento de la muerte, que no es otra cosa que la victoria final contra ese enemigo corporal ante el que la nueva andreia ha tenido que sostener tan larga batalla. ${ }^{11} \mathrm{El}$ alma es liberada de la prisión corporal que la atrapa. Y las últimas palabras del maestro no dejan espacio a la duda sobre la interpretación victoriosa del final: "Debemos un gallo a Asclepio", algo sobre lo que una escena previa se ha detenido ya, exponiendo la interpretación: la curación por la que Asclepio, dios de la medicina, debe ser recompensado es la misma muerte, liberadora de las turbaciones, miedos, dolores, anhelos, deseos y placeres ante los que el valeroso había tenido que oponer su esforzada resistencia.

\footnotetext{
${ }^{11}$ Cabe destacar que, aunque aquí se encuentra matizado y mediado por la actitud socráticoplatónica, el tema de la muerte y el buen morir no es en este en el único punto de la obra de Rossellini en el que puede encontrarse. Sobre ello puede consultarse el modo en que de nuevo Rancière trata la cuestión en "La caída de los cuerpos" (Rancière, 2005, 152-157), y la cita de Simone Weil que, en el transcurso de su análisis, nos recuerda: "La muerte es lo más precioso que ha recibido el hombre. Por eso la impiedad suprema es emplearla mal." (Weil, 1948, 100).
} 
La película en su conjunto es, de este modo, casi monográfica: un retrato detenido y detallado de una de las consecuencias de la teoría socrático-platónica de la virtud: el cambio en la noción de valor cívico. Un retrato minucioso en lo que respecta a detallar las condiciones de posibilidad que esta transformación abrió para nosotros. No se trata, por tanto, de limitarse a contar la vida de Sócrates, ni siquiera de establecerla como modelo, sino de mostrar su figura como punto de giro de algunas de las prenociones conformadoras de nuestra sociedad. Porque Sócrates fue quien fue, y porque cuestionó el sentido concreto de la tradición que cuestionó, es por lo que nuestra civilización ha ganado la posibilidad de entender y ejercer un nuevo concepto de valor y fuerza que ya no son exteriores a lo ético-político. Y por lo tanto se ha rebasado una suerte de "etapa arcaica" de la política y se ha recuperado lo heroico como ideal humano, alejado de toda mitología, de toda épica y de todo estado de excepción.

\section{Bibliografía}

BAssi, K. (2003) "The semantics of manliness in Ancient Greece”, en Rosen, R. M. y Sluiter, I. (eds.) Andreia: Studies in Manliness and Courage in Classical Antiquity. Brill: Leiden: 25-58.

Betegh, G. (2013) "Socrate et Archélaos dans les Nuées: Philosophie naturelle et éthique", en Laks, A. y Saetta Cottone, R. Comedie et philosophie: Socrate et les "Presocratiques" dans les Nuées d'Aristophane. Éditions Rue d'Ulm: Paris: 87-106.

Burnet, J. y Taylor, A. E. (1990) Varia socrática. Universidad Nacional Autónoma de México: México.

Calvo Martínez, T. (1995) De los sofistas a Platón: politica y pensamiento. Ediciones Pedagógicas: Madrid.

Cullyer, H. (2003) "Paradoxical andreia: Socratic echoes in Stoic 'manly courage", en Rosen, R. M. y Sluiter, I. (eds.) Andreia: Studies in Manliness and Courage in Classical Antiquity. Brill: Leiden: 213-233.

Jaeger, W. (1980) Paideia. Fondo de Cultura Económica: México.

JankéLÉVItch, V. (1982) La ironía o la buena conciencia. Taurus: Madrid.

Laks, A. y Saetta Cottone, R. (2013) Comedie et philosophie: Socrate et les "Presocratiques" dans les Nuées d'Aristophane. Éditions Rue d'Ulm: Paris.

Luri Medrano, G. (1998) El proceso de Sócrates: Sócrates y la transposición del socratismo. Trotta: Madrid. 
Menzel, A. (1964) Calicles: contribución a la historia de la teoría del derecho del más fuerte. Universidad Nacional Autónoma de México: México.

Montero Díaz, S. (1948) De Calicles a Trajano: Estudios sobre historia política del mundo antiguo. Instituto de Estudios Políticos: Madrid.

Moore, C. (2015) “Socrates and Self-Knowledge in Aristophanes' Clouds". The Classical Quarterly, 65: 534-551.

Pajón Leyra, I. (2004) "Calicles y Nietzsche: dos formas contrapuestas de entender el derecho del más fuerte”, en Nexo: revista de filosofía, n²: 167-176.

Platón (s. V a.C.) Diálogos. Gredos: Madrid.

RANCIÈRE, J. (2003) El maestro ignorante: cinco lecciones sobre la emancipación intelectual. Editorial Laertes: Barcelona.

RANCiÈRe, J. (2005) La fábula cinematográfica: reflexiones sobre la ficción en el cine. Paidós: Barcelona.

Rancière, J. (2012) “El cuerpo del filósofo: los filmes filosóficos de Rossellini”, en Las distancias del cine. Manantial: Buenos Aires: 87-101.

Rosen, R. M. y Sluiter, I. (2003) Andreia: Studies in Manliness and Courage in Classical Antiquity. Brill: Leiden.

TAYlor, A. E. (1961) El pensamiento de Sócrates. Fondo de Cultura Económica: México.

VAnder Waerdt, P. A. (1994) "Socrates in the Clouds", en Vander Waerdt, P. A. (ed.) The Socratic Movement. Cornell University Press: Ithaca.

Vlastos, G. (I99I) Socrates: Ironist and Moral Philosopher. Cornell University Press: Ithaca.

Weil, S. (1948) La Pesanteur et la Grâce. Plon: Paris.

Enviado: 3/02/2016

Aceptado: 7/04/2016

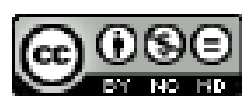

ENDOXA está bajo una licencia de Creative Commons Reconocimiento-NoComercial-SinObraDerivada 4.0 Internacional 